\title{
Influencing Factors and Promotion Strategies of Enterprise Safety Management Effectiveness
}

\author{
WANG Yuanshuai ${ }^{1, \mathrm{a} 1 \mathrm{st}}$, YANG Chunhui ${ }^{2,2 n d}, \mathrm{SHAO}$ FuZe ${ }^{3,3 \mathrm{rd}}$ \\ ${ }^{1}$ Department of Management Engineering and Equipment Economics, Naval University of Engineering Wuhan, China \\ ${ }^{2}$ Department of Management Engineering and Equipment Economics, Naval University of Engineering Wuhan, China \\ ${ }^{3}$ School of Economics and Management, Changzhou Institute of Technology Changzhou, China
}

\begin{abstract}
In order to deeply explore the influencing factors of corporate safety behavior management efficacy, this paper utilizes Chinese engineering corporations as research objects, the paper explores the impact of corporate safety culture and safety training investment on corporate safety management effectiveness, also the interacting impact of $\mathrm{f}$ corporate safety culture and safety training investment on corporate safety management efficacy. The empirical results show that corporate safety culture and safety training investment both have a positive impact on corporate safety management effectiveness, also the interacting effect is positive. The research in this paper therefore provides new solutions and perspective for improving the effectiveness of corporate security behavior management, which has great significance for management practice.
\end{abstract}

\section{Introduction}

What comes with the increasing complexity of engineering and technology is a significant rise on the pressure of enterprise safety management. Frequent safety incidents have caused huge social and economic losses. Therefore, enterprise safety management has become one of the priorities of industrial and academic communities and government departments. This paper discusses the influencing factors and provides a reference for enterprises to improve safety management, which is of great importance for the sound development of engineering enterprises.

In the practice of enterprise safety management, man, machine and environment are the inducing factors of safety accidents, among which man is the main factor ${ }^{[1]}$. Enterprise safety culture affects man mainly from physical, institutional and spiritual dimensions ${ }^{[1]}$. Therefore, to improve safety management effectiveness of enterprises, we can start from safety culture and strengthen management on human behavior. Enterprises generally invest resources to increase safety training according to their own situation. They may arrange certain personnel to better manage on-site safety. Such investment is mainly to improve workers' safety awareness and their equipment operation so as to reduce accidents ${ }^{[3]}$.

Given the differences in product attributes and safety management among enterprises in different industries, to effectively control the influence of industries on research results, the author selects Chinese engineering enterprises as the research data sources and discusses the influence of safety culture and training investment on safety management effectiveness. The paper establishes influencing factor models and can provide decisionmaking reference for Chinese engineering enterprises to improve their safety management effectiveness.

\section{Research Hypotheses and Model Construction}

\subsection{Enterprise Safety Culture and Safety Management Effectiveness}

In the safety management of engineering enterprises, an important dimension is safety culture, which affects safety management effectiveness of enterprises from physical, institutional and spiritual dimensions ${ }^{[2]}$. In physical dimension, enterprises mark the dangerous goods and provide employees with safety equipment. These measures positively influence safety management effectiveness; in institutional dimension, enterprises implement clear safety rules and regulations and penalty systems to regulate workers' behavior and let them understand expectations of enterprises. By doing so, enterprises hope their employees behave better than expected, thus positively affecting safety management effectiveness; in spiritual dimension, safety culture helps employees have a strong safety awareness and a correct view of safety and act with safety philosophies, thus positively affecting safety management effectiveness. Based on this, the paper proposes the first hypothesis:

Hypothesis 1: Enterprise safety culture positively influence safety management effectiveness. 


\subsection{Enterprise safety investment and safety management effectiveness}

The construction site is complex and with increasing safety risks. Thus, enterprises need to invest more to ensure the safety of construction, production and the safety of workers on site ${ }^{[1]}$. Through safety investment, the redundancy of organizational study can be reduced; the study of workers will be more targeted and effective; the innovation ability will be improved ${ }^{[2]}$ and enterprises will have more accurate prediction of employees' safety behavior ${ }^{[3]}$. Besides, employees will focus more on study and their stress can be relieved to some extent [4]. Enterprises send employees clear safety signals [5][6], which can help improve safety management effectiveness and reduce safety accidents. Based on this, the second hypothesis is proposed:

Hypothesis 2: Enterprise safety investment has a positive impact on safety management effectiveness.

\subsubsection{The interaction between safety culture and investment and safety management effectiveness}

Safety culture is a kind of enterprise culture, which has certain systematic and interactive features like enterprise factors. The interaction between safety culture and training investment can improve safety management effectiveness. Safety culture can promote enterprises to invest more in safety training and the investment can increase the positive influence of the physical, institutional and spiritual dimensions of safety culture on workers' safety behavior. In addition, the interaction can strengthen employees' self-conscious safety behavior ${ }^{[3]}$, thus further improving the management effectiveness. Therefore, this paper proposes the third hypothesis:

Hypothesis 3: The interaction between enterprise safety culture and investment has a positive impact on safety management effectiveness.

The theoretical model is shown in Figure 1.

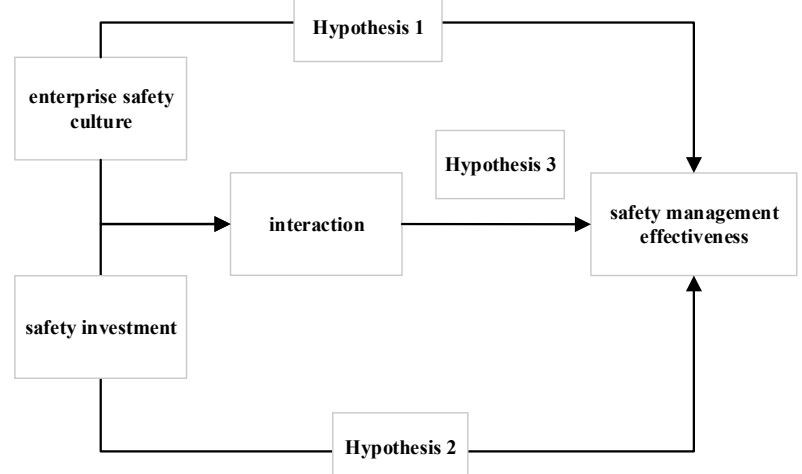

Fig 1. Theoretical Framework.

\section{Research Method}

\subsection{Investigation objects}

The paper takes the 100 independent project teams of 10 large engineering enterprises in China as investigation objects. The respondents to this questionnaire include project managers and all the other working staff (excluding labor dispatching employees). Each project team includes at least one project manager and four working staff. Among the 500 distributed questionnaires, 460 were collected. Invalid questionnaires (like those with incomplete answers) were excluded. The number of valid ones is 420 , meeting the research requirements. The details of enterprise are shown in Table 1.

Table1. Sample details

\begin{tabular}{|c|c|c|c|}
\hline Project & Type & $\begin{array}{c}\text { Sample } \\
\text { Size }\end{array}$ & $\begin{array}{c}\text { Proportion } \\
(\%)\end{array}$ \\
\hline \multirow{3}{*}{ Characteristics } & $\begin{array}{c}\text { State owned } \\
\text { enterprise (SOE) }\end{array}$ & 280 & 66.66 \\
\hline & Sole proprietorship & 75 & 18.76 \\
\hline & Joint venture & 65 & 15.48 \\
\hline \multirow{5}{*}{ Size } & $\leq 30$ & 45 & 10.71 \\
\hline & $30 \sim 60$ & 60 & 14.29 \\
\hline & $60 \sim 100$ & 100 & 23.81 \\
\hline & $100 \sim 200$ & 80 & 19.05 \\
\hline & $>200$ & 135 & 32.14 \\
\hline \multirow{4}{*}{ Age } & $\begin{array}{c}1 \sim 3 \text { (exclude } \\
3 \text { ) }\end{array}$ & 25 & 5.95 \\
\hline & $\begin{array}{c}3 \sim 6 \text { (exclude } \\
6 \text { ) } \\
\end{array}$ & 85 & 20.24 \\
\hline & $\begin{array}{c}6 \sim 10 \text { (exclude } \\
10 \text { ) }\end{array}$ & 115 & 27.38 \\
\hline & $\geq 10$ & 180 & 42.86 \\
\hline
\end{tabular}

\subsection{Research tools}

The author determines measurement scales by reviewing literature about safety management. Many experts, project managers of work groups and other staff are invited to ensure the feasibility of scales. This questionnaire adopts the 7-point Likert scale.

- The method of Mei Qiang ${ }^{[1]}$ et al. (2017) is adopted to measure the enterprise safety culture. The scale includes 14 measurement items in 3 dimensions. The results of confirmatory factor analysis (CFA) indicate that the safety culture model has a good construct validity $(\mathrm{NNFI}=0.936, \mathrm{NFI}=0.945$, CFI $=0.960$, RMSEA $=0.075$ ). Cronbach's Alpha coefficient of this scale is $0.904 .{ }^{[7][8]}$

- The calculation method of enterprise safety investment in this paper is as follows: the natural logarithm of safety investment each year is taken as the variable.

- The safety management effectiveness questionnaire in this paper is revised according to employee management effectiveness. The results of exploratory factor analysis show that this measurement has a good construct validity (NNFI $=0.906, \quad \mathrm{NFI}=0.925, \quad \mathrm{CFI}=0.934$, RMSEA $=0.045$ ). The Cronbach's Alpha coefficient of this scale is 0.916 . $^{[7][8]}$

- When designing the questionnaire, the following demographic variables are controlled: educational background, work seniority and gender (the values of male and female are 1 and 0 , respectively). 
Controlled enterprise variables include enterprise type (the values of SOE, sole proprietorship and joint venture are 3,2,1, respectively), enterprise size (the natural logarithm of the size is the variable) and age of enterprises.

\section{Results analysis}

\subsection{Discriminant validity of CFA}

The analysis results can be seen in Table 2. Enterprise safety culture and safety management effectiveness are two independent variables.

TABLE 2 CFA RESULTS

\begin{tabular}{|l|l|l|l|l|l|}
\hline Model & AIC & NNFI & CFI & RMR & RMSEA \\
\hline
\end{tabular}

Table 3 Variable mean, standard deviation and correlation analysis

\begin{tabular}{|c|c|c|c|c|c|c|c|c|}
\hline Variable & Mean & $\begin{array}{l}\text { Standard } \\
\text { deviation }\end{array}$ & 1 & 2 & 3 & 4 & 5 & 6 \\
\hline $\mathrm{X} 1$ & 3.79 & 0.85 & 1 & & & & & \\
\hline $\mathrm{Y}$ & 3.85 & 1.03 & $0.45 * *$ & $0.31 * *$ & 1 & & & \\
\hline SIZE & 4.03 & 11.49 & $0.13 * *$ & $0.29 * *$ & 0.16 & 1 & & \\
\hline $\mathrm{C} 1$ & 2.51 & 13.44 & $0.15 *$ & $0.24 *$ & $0.18 *$ & 0.27 & $0.32 *$ & 1 \\
\hline
\end{tabular}

where X1 represents enterprise safety culture; X2 is safety investment; Y denotes safety management effectiveness; SIZE represents the scale of enterprise; $\mathrm{C} 1$ denotes enterprise type. Here and elsewhere in this paper, $* * *$ means $\mathrm{p}<0.001 ; * *$ represents $\mathrm{p}<0.05 ; *$ means $\mathrm{p}<0.1$.

\subsection{Hypothesis testing}

The maximum VIF of all regression models is 2.78 , less than 10, indicating that multicollinearity between variables can be ruled out. ${ }^{[1][20]}$

In Model 1, all control variables are introduced, thus it is the benchmark model of hierarchical multiple regression. Model 2 introduces safety culture as the independent variable on the basis of control variables and the regression coefficient is 0.362 and $p<0.05$. Thus Hypothesis 1 is verified, namely, enterprise safety culture has a positive influence on safety management effectiveness. In Model 3, safety investment is introduced as a new independent variable and its regression coefficient is 0.181 and $p<0.05$. Thus, Hypothesis 2 is verified, namely, safety investment positively influences safety management effectiveness. The interaction between safety culture and safety investment is introduced in model 4 to investigate its influence on safety management effectiveness. And the regression coefficient is 0.115 and $\mathrm{p}<0.05$, so Hypothesis 3 is verified, namely, the interaction positively influences safety management effectiveness ${ }^{[13][14][15]}$. Now all the hypotheses in this paper have been verified, indicating that enterprise safety culture, training investment and the interaction between the two positively affect safety management effectiveness.

Table 4 Testing of interaction effect analysis

\begin{tabular}{|c|c|c|c|c|}
\hline \multirow{2}{*}{ Variable } & \multicolumn{4}{|c|}{ Y } \\
\cline { 2 - 5 } & Model 1 & Model 2 & Model 3 & Model 4 \\
\hline SIZE & 0.073 & 0.070 & 0.068 & 0.065 \\
\hline $\mathrm{AGE}$ & $0.161^{*}$ & $0.145^{*}$ & $0.138^{*}$ & $0.115^{*}$ \\
\hline $\mathrm{C} 1$ & 0.089 & 0.081 & 0.078 & 0.070 \\
\hline $\mathrm{X} 1$ & & $0.362^{* *}$ & $0.315^{* *}$ & $0.295^{* *}$ \\
\hline $\mathrm{X} 2$ & & & $0.181^{* *}$ & $0.175^{* *}$ \\
\hline $\mathrm{X} 1 * \mathrm{X} 2$ & & & & $0.115^{* *}$ \\
\hline $\begin{array}{c}\mathrm{F} \\
\text { VALUE }\end{array}$ & 7.502 & $24.560^{* *}$ & $26.654^{* *}$ & $28.621^{* * *}$ \\
\hline
\end{tabular}

\begin{tabular}{|c|c|c|c|c|c|}
\hline $\begin{array}{c}\text { SC, } \\
\text { SO }\end{array}$ & 75.731 & 0.945 & 0.965 & 0.041 & 0.046 \\
\hline $\begin{array}{c}\text { SC + } \\
\text { SO }\end{array}$ & 95.613 & 0.910 & 0.862 & 0.089 & 0.102 \\
\hline
\end{tabular}

where SC represents safety culture; SO denotes safety management effectiveness; "+" means that two factors are combined into one variable;

\subsection{Descriptive and Correlation Analysis}

In this paper, IBM SPSS 26 is adopted to calculate the correlation between variables, the mean and standard deviation. The results of descriptive and correlation analysis are shown in Table 3.

The results show that the correlation between variables is moderate. Therefore, the hypotheses can be tested. ${ }^{[9]}$ $* *$ represents $\mathrm{p}<0.01$.

\begin{tabular}{|c|c|c|c|c|}
\hline $\mathrm{R} 2$ & 0.097 & 0.245 & 0.270 & 0.291 \\
\hline$\triangle \mathrm{R} 2$ & 0.096 & 0.148 & 0.173 & 0.194 \\
\hline \multicolumn{5}{|c}{$* *$ means $\mathrm{p}<0.001 ; * *$ represents $\mathrm{p}<0.05 ; *$ means $\mathrm{p}<0.1$. }
\end{tabular}

\section{Conclusion}

The results of this paper show that enterprise safety culture and training investment positively influence safety management effectiveness. The paper also explains how the safety culture and safety training investment influence safety management effectiveness. The paper can encourage enterprises to invest more in safety training, thus improving safety management effectiveness.

1) This paper selects Chinese engineering enterprises as research samples and more researches can be done in the subindustries to make the conclusions more convincing.

2) Many intertwined factors influence the effectiveness of enterprise safety management. So how other factors affect safety management effectiveness can be discussed.

3) Affected by some subjective factors of scorers, the ratings of enterprise safety culture and safety management effectiveness in this paper may show certain subjectivity. Therefore, in the future, subjective and objective data and dynamic data (combining cross sectional data and longitudinal data) can be used to explore the influencing factors, thus providing more effective decision-making reference for enterprises to improve safety management effectiveness.

\section{References}

1. MEI Qiang, ZHANG Chao, LI Wen. The relationship between Safety Culture, Safety Atmosphere and 
Employee Safety Behavior - Evidence from SMEs in high-risk industries [J]. Journal of System \& Management, 2017, 02(26): 277-286.

2. SUN Yin, ZOU Bo, GUO Jinyu, GUO Feng. Firm Innovation in Context of Technological Turbulence: Based on Dual Perspective of Organizational Slack and Learning [J]. Journal of System \& Management, 2020, 01(29): 41-48.

3. WEI Wu, ZHAO He, XIAO Deyun . Organizational learning and firm's forecasting ability based on the perspective of organizational attention. [J]. Science Research Management, 2019, 40(2):144-153.

4. JIANG Lan, LIU Yaqin, SUN Jia. Research on relationship between work stress and unsafe behaviors of airport security staff. [J]. China Safety Science Journal, 2019 ,04(29):13-18.

5. LIU Yisong. Discussion of unsafe behavior in safety management $[\mathrm{J}]$. West-China Exploration Engineering, 2005(6): 226-228.

6. ZHANG Mengchun, FANG Dongping, TONG Ruipeng. Study on underestimating risks of scaffolders to unsafe behaviors [J]. China Safety Science Journal, 2011, 21(8):145-150.

7. Liao Junyun, Lin Xiaoxin, Wei Haiying. How Does Online Brand Community Value Influence Consumer's Continuous Participation? The Moderating Role of Brand Knowledge [J]. Nankai Business Review, 2019, 22 (6): 16-22.

8. Xu Yangyang, Lin Xinqi, Xi Yiheng. How will the Lonely Employee be More Engaged in: Research on the Moderation Effect of Future Work Self Salience and Transformational Leadership [J]. Nankai Business Review, 2019, 22 (5): 79-89.

9. GUO Ren, ZHOU Fei, LIN Chunpei. Impact of organizational knowledge sharing atmosphere on management innovation: A model based on the employee self - efficacy's moderated mediation effect. [J]. Science Research Management, 2018, 10 (39):70-78.

10. ZHANG Yong, LIU Haiquan, WANG Mingxuan, QING Ping. The impact of challenge stress and hindrance stress on employee creativity: the mediating role of self-efficacy and the moderating role of justice, 2018,4(50):450-461.

11. HE Huitao, YUAN Yongzhi. The influence of Network Embeddedness and Interaction Effects on the Performance of Overseas Talent Entrepreneurship [J]. Chinese Journal of Management, 2018，01（15）: 66-73.

12. ZHAO ShuSong, ZHAO Jun, LIAO JianQiao. Developmental Performance Appraisal and Employees' Knowledge Sharing: A Model of Mediated Moderation [J]. Journal of Industrial Engineering and Engineering Management, 2016, 30(4): 45-52.

13. LIU Jun. Management Research Technique: Theory and applications. [M]. Beijing: China Renmin University Publishing Press, 2008: 348-352.
14. LIU Xiaoyu, LIU Jun, YU Guangtao. Preemployment Beliefs, Organizational Inducement, and Psychological Contract Change: A Longitudinal Study [J]. Acta Psychologica Sinica, 2008,40(1): 6473.

15. ZHANG Chi, ZHANG Zhaoguo, BAO Lili. A Study on the Interactive and Intertemporal Influence and Mechanism of Corporate Environmental Responsibility and Financial Performance [J]. Management Review, 2020, 32(2): 76-89. 